\title{
(6) OPEN ACCESS \\ Systematic review of the toxicity of short-course oral corticosteroids in children
}

\author{
Fahad Aljebab, Imti Choonara, Sharon Conroy
}

Division of Medical Sciences \& Graduate Entry Medicine, School of Medicine, University of Nottingham, Royal Derby Hospital Centre, Derby, UK

\section{Correspondence to}

Dr Sharon Conroy, Division of Medical Sciences \& Graduate

Entry Medicine, School of Medicine, University of Nottingham, Royal Derby Hospital Centre, Uttoxeter Road, Derby DE22 3DT, UK; Sharon.conroy@nottingham. ac.uk

Received 10 August 2015 Revised 2 December 2015 Accepted 3 December 2015 Published Online First 14 January 2016

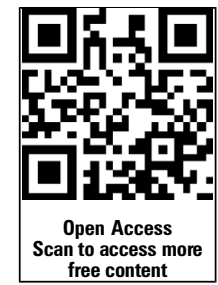

CrossMark

To cite: Aljebab $F$

Choonara I, Conroy S. Arch

Dis Child 2016;101:

365-370.

\section{ABSTRACT}

Background Short-course oral corticosteroids are commonly used in children but are known to be associated with adverse drug reactions (ADRs). This review aimed to identify the most common and serious $A D R s$ and to determine their relative risk levels. Methods A literature search of EMBASE, MEDLINE, International Pharmaceutical Abstracts, CINAHL, Cochrane Library and PubMed was performed with no language restrictions to identify studies in which oral corticosteroids were administered to patients aged 28 days to 18 years of age for up to and including 14 days of treatment. Each database was searched from their earliest dates to December 2013. All studies providing clear information on ADRs were included. Results Thirty-eight studies including 22 randomised controlled trials (RCTs) met the inclusion criteria. The studies involved a total of 3200 children in whom 850 ADRs were reported. The three most frequent ADRs were vomiting, behavioural changes and sleep disturbance, with respective incidence rates of $5.4 \%, 4.7 \%$ and $4.3 \%$ of patients assessed for these ADRs. Infection was one of the most serious ADRs; one child died after contracting varicella zoster. When measured, 144 of 369 patients showed increased blood pressure; 21 of 75 patients showed weight gain; and biochemical hypothalamic-pituitary-adrenal axis suppression was detected in 43 of 53 patients.

Conclusions Vomiting, behavioural changes and sleep disturbance were the most frequent ADRs seen when short-course oral corticosteroids were given to children. Increased susceptibility to infection was the most serious ADR.

Trial registration number CRD42014008774. By PROSPERO International prospective register of systematic reviews.

\section{INTRODUCTION}

For over 50 years, corticosteroids have been used in a wide array of medical conditions as therapeutic and diagnostic tools, predominantly for their immunosuppressant and anti-inflammatory properties. Adverse drug reactions (ADRs) to corticosteroids are known to be associated with the size of the dose, the route of administration and the length of time for which the drug is prescribed. Many ADRs have been reported, such as mood and behaviour changes, vomiting, hypothalamic-pituitary-adrenal (HPA) axis suppression, increased blood pressure and insomnia.

The duration of corticosteroid therapy varies depending on the medical condition being treated and the pathology of the patient. Different definitions have been used for short duration or short courses of corticosteroids. The current British

\section{What is already known on this topic}

- Short-course oral corticosteroids are widely used in children to treat conditions such as asthma and croup.

- Corticosteroids are known to be associated with many adverse drug reactions (ADRs).

\section{What this study adds}

Vomiting, changes in behaviour and sleep disturbance are the most frequent ADRs associated with short courses of corticosteroids. The incidence for each is between $5.4 \%$ and $4.3 \%$.

- Vomiting is the most common reason for discontinuing corticosteroids.

- Increased susceptibility to infection is the most serious ADR associated with short courses of corticosteroids, with up to $1 \%$ of patients experiencing it.

guideline for treatment of acute asthma advises using oral corticosteroids from 3 to 7 days, ${ }^{1}$ however the previous guideline (2008) advised use from 7 to 14 days. $^{2}$

While ADRs caused by corticosteroids are well recognised and documented in the summaries of product characteristics (SPC) for relevant products, the toxicity of short-course oral corticosteroids has not been extensively evaluated and their relative risks are unclear. We therefore performed a systematic review to determine the toxicity associated with short-course oral corticosteroids, to identify the most common and serious ADRs and to determine their relative risk levels. We defined shortcourse oral corticosteroids as use for 14 days or less.

\section{METHODS}

A systematic literature search was performed to identify all papers describing toxicity of corticosteroids in children. Six databases were searched up to December 2013: MEDLINE, EMBASE, International Pharmaceutical Abstracts, CINAHL, Cochrane Library and PubMed. The databases were searched separately and combined together to remove duplications. The search strategy included all languages and involved the keywords "prednis" or dexamethasone or betamethasone' which are the 


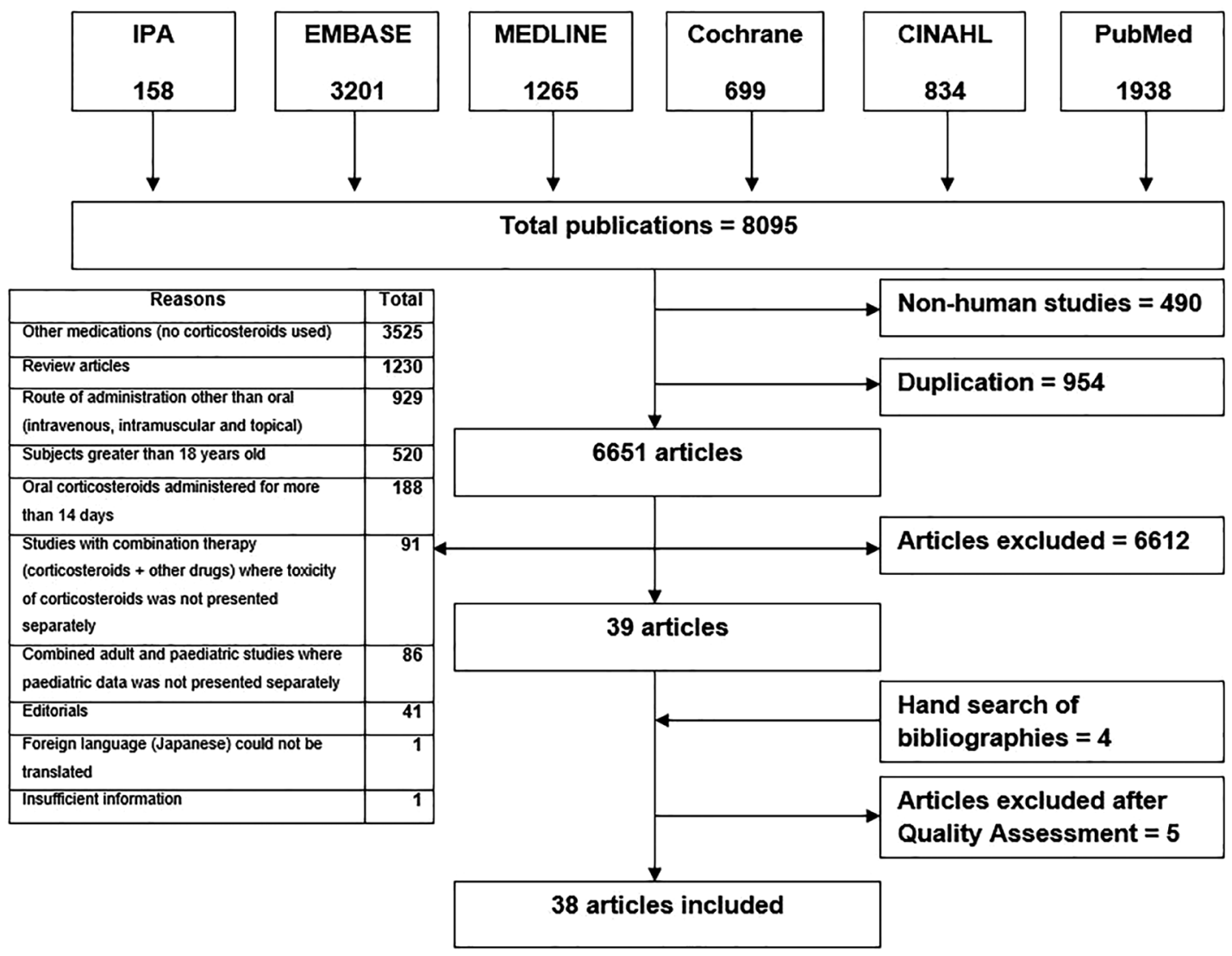

Figure 1 Flow chart of the literature search performed.

most frequent medications given orally to children for short periods. 'Corticosteroid' was added to cover all other oral corticosteroid medication. The keywords "toxicity" or adverse drug reaction* or adverse event* or side effect* or adverse effect*" were used as recommended by the BMC Medical Research Methodology for systematic reviews of adverse effects. ${ }^{3}$ Additionally, the keyword 'safety"' was used as in a previous systematic review. ${ }^{4}$ The terms recommended by search strategies for MEDLINE were used to cover the paediatric age group "child" or children* or $\mathrm{p}^{*}$ ediatric" or infant" or adolescent", The terms neonate, newborn and gestation were excluded. The keywords oral, tablet, syrup and PO (abbreviation meaning by mouth) were used to cover all possibilities of oral administration of corticosteroids.

Inclusion criteria were original research studies assessing corticosteroid toxicity in children from 28 days up to 18 years of age. These included randomised controlled trials (RCTs), case series, case reports, cohort studies and letters. Five per cent of randomly selected abstracts were independently assessed for eligibility by a second reviewer for assurance that no relevant studies were missed. Data including the number of patients, drug name, duration of use, diagnosis, number and type of ADRs were extracted.

Exclusion criteria included review articles, editorials, studies that did not give ADR data, studies in adults, studies involving adults and children in which paediatric data were not presented separately, and studies in which corticosteroids were not given orally and/or were administered for more than 14 days.

Meta-analysis of included RCTs was performed using RevMan 5.2. This is software provided by Cochrane, used for organising the quality assessment for RCTs and for carrying out meta-analysis. The quality of included RCTs was assessed using

Table 1 Summary of included articles

\begin{tabular}{|c|c|c|c|c|c|c|c|}
\hline \multirow[b]{2}{*}{ Type of study } & \multirow[b]{2}{*}{ No. of studies } & \multicolumn{3}{|l|}{ No. of patients } & \multicolumn{3}{|c|}{ No. of adverse drug reactions } \\
\hline & & Prednisolone & Dexamethasone & Betamethasone & Prednisolone & Dexamethasone & Betamethasone \\
\hline $\mathrm{RCT}^{*}$ & 22 & 1879 & 984 & 0 & 344 & 162 & 0 \\
\hline Prospective cohort studies & 5 & 125 & 180 & 0 & 183 & 110 & 0 \\
\hline Case series (CS) & 2 & 20 & 0 & 0 & 26 & 0 & 0 \\
\hline Case report (CR) & 9 & 10 & 0 & 2 & 18 & 0 & 7 \\
\hline Total & 38 & 2034 & 1164 & 2 & $571+$ & $272 \dagger$ & $7 \dagger$ \\
\hline
\end{tabular}


Table 2 Observed/reported adverse drug reactions (ADRs) from RCTs and prospective cohort studies

\begin{tabular}{|c|c|c|c|c|c|}
\hline \multirow[b]{2}{*}{$\begin{array}{l}\text { Adverse } \\
\text { effects }\end{array}$} & \multirow[b]{2}{*}{$\begin{array}{l}\text { No. of } \\
\text { patients } \\
\text { with } \\
\text { ADRs }\end{array}$} & \multirow[b]{2}{*}{$\begin{array}{l}\text { No. of } \\
\text { studies } \\
\text { reporting } \\
\text { ADR }\end{array}$} & \multicolumn{2}{|c|}{ Denominators } & \multirow[b]{2}{*}{$\begin{array}{l}\text { Incidence } \\
(\%)\end{array}$} \\
\hline & & & $\begin{array}{l}\text { No. of } \\
\text { studies } \\
\text { looking } \\
\text { for ADR }\end{array}$ & $\begin{array}{l}\text { Total } \\
\text { no. of } \\
\text { patients }\end{array}$ & \\
\hline Vomiting & 151 & 14 & 19 & 2810 & 5.4 \\
\hline $\begin{array}{l}\text { Disturbance in } \\
\text { behaviour }\end{array}$ & 113 & 6 & 16 & 2390 & 4.7 \\
\hline $\begin{array}{l}\text { Sleep } \\
\text { disturbance }\end{array}$ & 101 & 2 & 14 & 2342 & 4.3 \\
\hline Nausea & 45 & 4 & 15 & 2428 & 1.9 \\
\hline $\begin{array}{l}\text { Increased } \\
\text { appetite }\end{array}$ & 40 & 3 & 15 & 2378 & 1.7 \\
\hline $\begin{array}{l}\text { Abdominal } \\
\text { pain }\end{array}$ & 32 & 5 & 16 & 2514 & 1.3 \\
\hline $\begin{array}{l}\text { Facial swelling } \\
\text { and flushing }\end{array}$ & 27 & 2 & 15 & 2378 & 1.1 \\
\hline Infection & 20 & 5 & 13 & 2242 & 0.9 \\
\hline $\begin{array}{l}\text { Facial } \\
\text { erythema }\end{array}$ & 13 & 1 & 14 & 2328 & - \\
\hline $\begin{array}{l}\text { Others } \\
\text { gastrointestinal }\end{array}$ & 7 & 1 & 13 & 2242 & - \\
\hline Cough & 5 & 2 & 13 & 2242 & 0.2 \\
\hline Drowsiness & 5 & 1 & 13 & 2242 & - \\
\hline $\begin{array}{l}\text { Throat } \\
\text { irritation }\end{array}$ & 2 & 1 & 13 & 2242 & - \\
\hline Diarrhoeal & 2 & 1 & 14 & 2328 & - \\
\hline $\begin{array}{l}\text { Excessive } \\
\text { urination }\end{array}$ & 1 & 1 & 13 & 2242 & - \\
\hline Rash & 1 & 1 & 13 & 2242 & - \\
\hline
\end{tabular}

the Cochrane collaborations tool for assessing risk of bias in randomised trials. ${ }^{6}$ Any study showing a high risk of bias on three or more parameters was thereafter excluded.

Prospective cohort studies were assessed using the Strengthening the Reporting of Observational Studies in Epidemiology (STROBE) checklist, ${ }^{7}$ for which a score of over $70 \%$ is required for inclusion. Other studies were quality assessed using the Health Technology Assessment checklist. ${ }^{8}$ All studies achieving at least satisfactory criteria were included. All quality assessments were independently assessed for eligibility and scored by two reviewers using a specially designed form. Any discrepancies were resolved by a third reviewer.

The incidence of ADRs was calculated from the RCTs and prospective cohort studies when more than one study reported the ADR.

\section{RESULTS}

Eight thousand and ninety-five articles were identified in total. Thirty-eight articles met the inclusion criteria after four papers were added from manual searches of bibliographies, ${ }^{9-46}$ and five articles were excluded after quality assessment. The remaining articles were excluded for the reasons shown in figure 1 .

Corticosteroids were used to manage various medical conditions, including asthma, bronchiolitis, croup, acute renal failure, allergic rhinitis, dengue fever, infantile spasms, nephrotic syndrome, acute leukaemia, acute idiopathic thrombocytopenic purpura and systemic lupus erythematosus. Prednisolone and dexamethasone were the most commonly used drugs.

The studies included a total of 3200 patients and 850 ADRs (table 1). RCTs accounted for over half of the studies, $89 \%$ of patients and $60 \%$ of ADRs. ${ }^{9-30}$ The five prospective cohort studies included less than $10 \%$ of patients $(n=305)$ but reported one-third of the ADRs. ${ }^{31-35}$ Prospective cohort studies detected more ADRs per patient than RCTs.

- Thirteen studies looked for all possible symptomatic adverse events $^{10}{ }^{12-16} 18 \quad 2124 \quad 27-30$ and one of them also evaluated HPA axis suppression. ${ }^{20}$

- Four studies looked for vomiting only, ${ }^{9} 11 \quad 22 \quad 26$ and one study looked specifically for vomiting, nausea and abdominal pain. $^{34}$

- Two studies evaluated HPA axis suppression only, ${ }^{17} 35$ and one study evaluated blood pressure and HPA axis suppression. ${ }^{19}$

- One study looked for sleep disturbance only, ${ }^{33}$ one for behavioural change only, ${ }^{32}$ and one evaluated bone mineralisation only. $^{20}$

- Two studies were questionnaires based on parental response to specific questions about specific ADRs such as behavioural changes. ${ }^{23} 31$

- One study evaluated patient's blood pressure and blood glucose. ${ }^{25}$

Overall, six studies measured patient's blood pres-

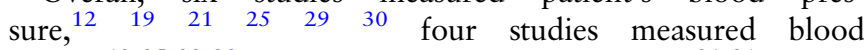
glucose $^{12252930}$ and two studies measured weight. ${ }^{21} 31$

Twenty-one different ADRs were reported from the RCTs and prospective cohort studies (tables 2 and 3). The three most common side effects were vomiting, changes in behaviour and disturbed sleep, affecting between $5.4 \%$ and $4.3 \%$ of children.

Six RCTs evaluated blood pressure in 369 patients. Four studies reported increased blood pressure in 144 of 186 patients. ${ }^{19} 212530$ Two studies showed no change in blood pressure in 183 patients. $^{12} 29$ Overall, 39\% of patients measured showed increased blood pressure. The definition of increased blood pressure varied between studies. One study defined it as

Table 3 Adverse drug reactions (ADRs) from RCTs and prospective cohort studies requiring specific measurements

\begin{tabular}{|c|c|c|c|c|c|}
\hline \multirow[b]{2}{*}{ Adverse effects } & \multirow[b]{2}{*}{$\begin{array}{l}\text { No. of patients } \\
\text { with ADRs }\end{array}$} & \multirow[b]{2}{*}{$\begin{array}{l}\text { No. of studies } \\
\text { reporting ADR }\end{array}$} & \multicolumn{2}{|l|}{ Denominators } & \multirow[b]{2}{*}{ Incidence (\%) } \\
\hline & & & $\begin{array}{l}\text { No. of studies } \\
\text { looking for ADR }\end{array}$ & Total no. of patients & \\
\hline Increased blood pressure & 144 & 4 & 6 & 369 & 39 \\
\hline HPA axis suppression & 43 & 4 & 4 & 53 & 81 \\
\hline Weight gain & 21 & 2 & 2 & 75 & 28 \\
\hline Hyperglycaemia & 15 & 2 & 4 & 338 & 4.4 \\
\hline Decreased bone mineralisation & 11 & 1 & 1 & 11 & - \\
\hline
\end{tabular}




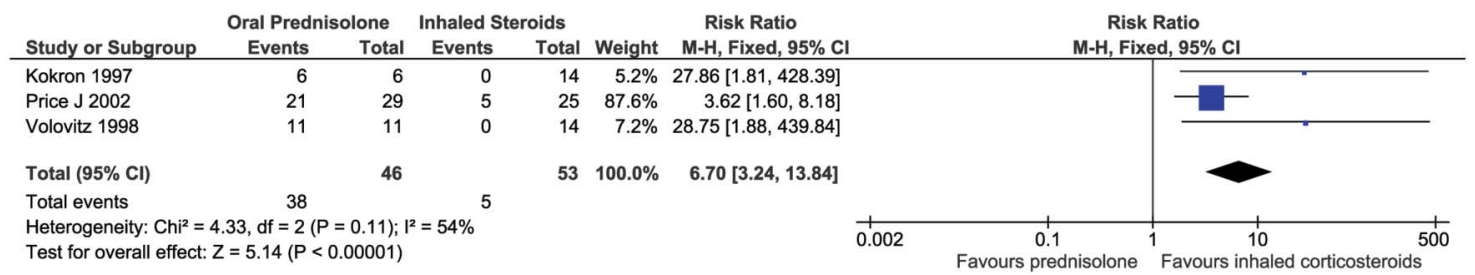

Figure 2 Relative risk of hypothalamic-pituitary-adrenal axis suppression: oral prednisolone and inhaled corticosteroids. ${ }^{17-19}$

diastolic blood pressure $>85 \mathrm{~mm} \mathrm{Hg} .{ }^{21}$ Mean increases of 3-7 $\mathrm{mm} \mathrm{Hg}$ were described in one study. ${ }^{25}$

Four studies (three RCTs, one prospective cohort study) and one case series specifically evaluated HPA axis suppression. ${ }^{17-19} 3536$ Forty-three of the 53 patients tested showed biochemical HPA axis suppression. Meta-analysis across three RCTs showed statistically significant biochemical HPA axis suppression associated with oral corticosteroids compared with inhaled corticosteroids (fixed model, $\mathrm{I}^{2}=54 \%, \mathrm{p}=0.00001, \mathrm{RR}=6.7$ ). This risk was greater with oral prednisolone than with inhaled budesonide, nebulised fluticasone and intranasal beclomethasone (figure 2).

Eighteen different ADRs were reported from case series and case reports with a total of 51 ADRs in 31 patients (table 4). Varicella zoster infection was reported in three patients taking oral prednisolone. ${ }^{39-41}$ All were admitted to intensive care and one died.

Medication was stopped in 44 patients due to ADRs. The rate of discontinuation was $1.4 \%$. Vomiting was the most common reason from seven RCTs and involved 36 children (35 with prednisolone and one child with dexamethasone). ${ }^{9} 101415222627$ Behavioural changes were the second most common reason for discontinuing the medication (four children) from two $\mathrm{RCTs}^{3033}$ and one cohort study. ${ }^{42}$ The ADR resulting in discontinuation was not stated for three children in one RCT. ${ }^{16}$

Table 4 Adverse drug reactions (ADRs) from case series and case reports

\begin{tabular}{|c|c|c|}
\hline Adverse effects & $\begin{array}{l}\text { No. of patients } \\
\text { with ADRs }\end{array}$ & Outcome \\
\hline $\begin{array}{l}\text { Disturbance in mood and } \\
\text { behaviour }\end{array}$ & 11 & 1 stopped medication \\
\hline Weight gain & 9 & \\
\hline Hypertriglyceridemia & 5 & \\
\hline Urticaria & 4 & \\
\hline Angioedema & 4 & \\
\hline Infection (varicella) & 3 & $\begin{array}{l}1 \text { died (all admitted to } \\
\text { intensive care unit) }\end{array}$ \\
\hline HPA axis suppression & 3 & \\
\hline vomiting & 2 & \\
\hline Increased blood pressure & 1 & \\
\hline Sudoresis & 1 & \\
\hline Rash & 1 & 1 stopped medication \\
\hline Impending doom & 1 & \\
\hline Lost consciousness & 1 & \\
\hline Headache & 1 & \\
\hline Hypocalcaemia & 1 & \\
\hline Increased ocular pressure & 1 & \\
\hline Ocular pain & 1 & \\
\hline \multirow[t]{2}{*}{ Photophobia } & 1 & \\
\hline & $51^{*}$ & \\
\hline
\end{tabular}

Three studies compared prednisolone (base) tablet or syrup and oral dexamethasone for the risk of vomiting. ${ }^{11} \quad 14 \quad 15$ Vomiting was reported in 38 out of 411 children taking prednisolone, and 11 out of 416 children taking dexamethasone. The risk of vomiting was significantly greater with prednisolone base tablet or syrup (figure 3) (fixed model, $\mathrm{I}^{2}=30 \%, \mathrm{p}=0.0001$, $\mathrm{RR}=3.62$ ). Prednisolone sodium phosphate solution, however, had a lower risk of vomiting than both (prednisolone (base) solution and oral dexamethasone). ${ }^{22} 34$

Three studies (one RCT, one cohort study and one case series) evaluated weight changes in patients. ${ }^{21} 3137$ Thirty of the 84 patients measured showed weight gain. The definition of an increase in body weight varied between studies, one study defined the increase in body weight as more than $500 \mathrm{~g}$ over the pretreatment value. ${ }^{21}$

\section{DISCUSSION}

The most serious side effect associated with short courses of oral corticosteroids was infection due to their immunosuppressant action. Five RCTs reported that 20 children experienced infection during treatment periods (incidence 0.9\%). Three cases were reported of children infected with varicella zoster, one of whom died and the other two were admitted to the intensive care unit with severe complications. ${ }^{39-41}$

HPA axis suppression is another potentially serious ADR associated with the use of oral corticosteroids. This suppression may lead to stress-induced acute adrenal crisis or growth retardation. In four studies specifically looking for this, 43 children showed a statistically significant biochemical suppression of the HPA axis. One case series also showed a significant occurrence of transient HPA axis suppression in 3 of 11 children with a 5-day course of prednisolone $(2 \mathrm{mg} / \mathrm{kg} / \mathrm{day})$. All the children returned to a normal level of endogenous cortisol secretion within 10 12 days after discontinuation of the corticosteroids. ${ }^{17-19} 35 \quad 36$ Overall, when this was measured, $81 \%$ of children receiving short-course oral corticosteroids showed biochemical HPA axis suppression. Studies in adults suggest that high-dose oral prednisolone $(50 \mathrm{mg} /$ day $)$ for 5 days does not suppress the HPA axis. ${ }^{47}$ A recent study found no differences between shortcourse oral and inhaled corticosteroids in terms of biochemical HPA axis suppression ${ }^{48}$ and stated that the clinical consequences of biochemical suppression needs further study.

The three most commonly observed ADRs associated with short-course oral corticosteroids were vomiting, changes in behaviour and disturbed sleep. Vomiting was the most common side effect with an incidence of 5.4\% of patients and was the most frequent reason for withdrawal of oral corticosteroids. Our systematic review suggests that different dosage forms of oral prednisolone had a different incidence of vomiting. Prednisolone sodium phosphate solution was less likely to cause vomiting than other formulations (prednisolone base solution and dexamethasone solution). ${ }^{22} 34$

Mood swings and behavioural disturbance were the second most frequently observed adverse events with an incidence of 


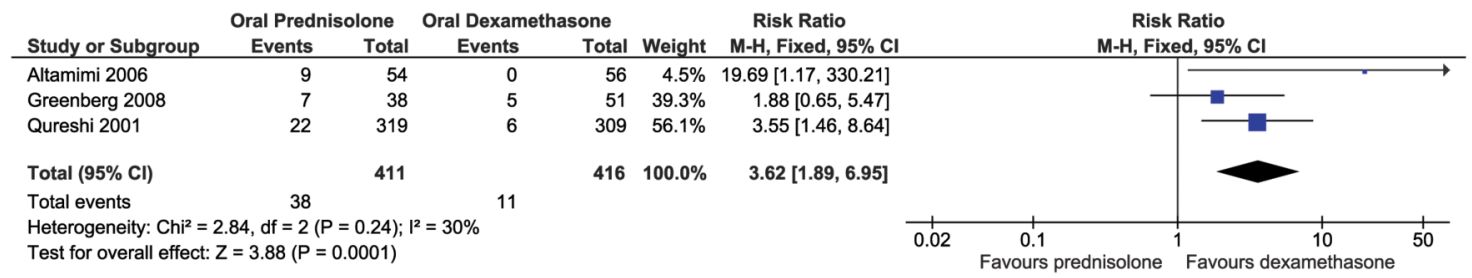

Figure 3 Relative risk of vomiting: prednisolone (base) tablet or syrup and dexamethasone. ${ }^{11} 1415$

4.7\%. Mood swings (anxiety, hyperactivity and aggressive behaviour) were significantly more frequent with higher doses $\left(2 \mathrm{mg} / \mathrm{kg} /\right.$ day or $60 \mathrm{mg} / \mathrm{m}^{2} /$ day) of oral prednisolone than with lower doses $\left(1 \mathrm{mg} / \mathrm{kg} /\right.$ day). ${ }^{23} 3132$ In adult patients, behaviour and mood changes were distinctly less common at doses of prednisolone under $20 \mathrm{mg} /$ day compared with patients who received $60 \mathrm{mg} /$ day. $^{49}$

Sleep disturbance was the third most frequent observed adverse event caused by oral corticosteroids, with an incidence of $4.3 \%$. Two studies (one RCT and one cohort study) reported 101 children had sleep disturbances. An observational study also reported that all children who received oral dexamethasone for the treatment of leukaemia experienced sleep disturbance. ${ }^{33}$ One RCT reported an infant who received oral prednisolone for the treatment of infantile spasms with this event. ${ }^{30}$

Corticosteroids lead to an increase in blood pressure by increasing the resistance in the body's vascular system, increasing intracellular volume, and increasing cardiac contractility. Overall, even though more than one-third of the children tested experienced an increase in blood pressure, the majority did not need antihypertensive drugs or withdrawal of medication. Two patients with infantile spasms had an increase in blood pressure above $120 / 90 \mathrm{~mm} \mathrm{Hg}$ and received diuretics without stopping their medication. ${ }^{30}$ The clinical significance of raised blood pressure following short-course corticosteroids needs further study.

Prospective cohort studies were the most effective at detecting ADRs. RCTs are the gold standard for determining effectiveness of therapy, but are often underpowered to evaluate toxicity.

In conclusion, this systematic review showed the most serious ADR associated with short-course oral corticosteroids was infection which was reported in $1 \%$ of patients. The most frequent ADRs were vomiting, behavioural change and sleep disturbance. Vomiting was the main reason for treatment discontinuation. Weight gain was experienced by more than one-third of patients when this was measured.

Contributors FA, IC and SC conceived the idea and designed the study as part of FA's PhD. FA did the literature search and extracted the data and wrote the first draft. IC and SC reviewed and validated the extracted data and revised the paper.

Competing interests None declared.

Provenance and peer review Not commissioned; externally peer reviewed.

Open Access This is an Open Access article distributed in accordance with the Creative Commons Attribution Non Commercial (CC BY-NC 4.0) license, which permits others to distribute, remix, adapt, build upon this work non-commercially, and license their derivative works on different terms, provided the original work is properly cited and the use is non-commercial. See: http://creativecommons.org/ licenses/by-nc/4.0/

\section{REFERENCES}

1 British Thoracic Society/Scottish Intercollegiate Guidelines Network. British Guideline on the Management of Asthma. 2014. https://www.brit-thoracic.org.uk/ guidelines-and-quality-standards/asthma-guideline/

2 Douglas G, Higgins B, Barnes N, et al. British Guideline on the Management of Asthma. Thorax 2008;63(Suppl 4):71.
3 Loke YK, Price D, Herxheimer A. Systematic reviews of adverse effects: framework for a structured approach. BMC Med Res Methodol 2007;7:32.

4 Egunsola 0, Adefurin A, Fakis A, et al. Safety of fluconazole in paediatrics: a systematic review. Eur J Clin Pharmacol 2013;69:1211-21.

5 Kastner M, Wilczynski NL, Walker-Dilks C, et al. Age-specific search strategies for Medline. J Med Internet Res 2006;8:e25.

6 Higgins JPT, Altman DG, Gøtzsche PC, et al. The Cochrane Collaboration's tool for assessing risk of bias in randomised trials. BMJ 2011;343:d5928.

7 von Elm E, Altman DG, Egger M, et al. Strengthening the Reporting of Observational Studies in Epidemiology (STROBE) statement: guidelines for reporting observational studies. BMJ 2007;335:806-8.

8 Maund E, Craig D, Suekarran S, et al. Management of frozen shoulder: a systematic review and cost-effectiveness analysis. Health Technol Assess 2012;16:1-264.

9 Scarfone RJ, Loiselle JM, Wiley JF, et al. Nebulized dexamethasone versus oral prednisone in the emergency treatment of asthmatic children. Ann Emerg Med 1995;26:480-6.

10 Gordon S, Tompkins T, Dayan PS. Randomized trial of single-dose intramuscular dexamethasone compared with prednisolone for children with acute asthma. Pediatr Emerg Care 2007;23:521-7.

11 Greenberg RA, Kerby G, Roosevelt GE. A comparison of oral dexamethasone with oral prednisone in pediatric asthma exacerbations treated in the emergency department. Clin Pediatr (Phila) 2008;47:817-23.

12 Becker JM, Arora A, Scarfone RJ, et al. Oral versus intravenous corticosteroids in children hospitalized with asthma. J Allergy Clin Immunol 1999;103:586-90.

13 Rittichier KK, Ledwith CA. Outpatient treatment of moderate croup with dexamethasone: intramuscular versus oral dosing. Pediatrics 2000;106:1344-8.

14 Qureshi F, Zaritsky A, Poirier MP. Comparative efficacy of oral dexamethasone versus oral prednisone in acute pediatric asthma. J Pediatr 2001;139:20-6.

15 Altamimi S, Robertson G, Jastaniah W, et al. Single-dose oral dexamethasone in the emergency management of children with exacerbations of mild to moderate asthma. Pediatr Emerg Care 2006;22:786-93.

16 Manjra Al, Price J, Lenney W, et al. Efficacy of nebulized fluticasone propionate compared with oral prednisolone in children with an acute exacerbation of asthma. Respir Med 2000;94:1206-14.

17 Volovitz B, Bentur L, Finkelstein Y, et al. Effectiveness and safety of inhaled corticosteroids in controlling acute asthma attacks in children who were treated in the emergency department: a controlled comparative study with oral prednisolone. J Allergy Clin Immunol 1998;102:605-9.

18 Price J, Lenney W, Duncan C, et al. HPA-axis effects of nebulised fluticasone propionate compared with oral prednisolone in childhood asthma. Respir Med 2002;96:625-31.

19 Kokron CM, Castro AS, Solé D, et al. Lysine-vasopressin in the evaluation of the hypothalamic-pituitary-adrenal axis in children with allergic rhinitis treated with intranasal beclomethasone dipropionate or oral prednisone. J Investig Allergol Clin Immunol 1997;7:51-6.

20 Wolthers OD, Riis BJ, Pedersen S. Bone turnover in asthmatic children treated with oral prednisolone or inhaled budesonide. Pediatr Pulmonol 1993;16:341-6.

21 Orta-Sibu N, Chantler C, Bewick M, et al. Comparison of high-dose intravenous methylprednisolone with low-dose oral prednisolone in acute renal allograft rejection in children. Br Med J (Clin Res Ed) 1982;285:258-60.

22 Kim MK, Yen K, Redman RL, et al. Vomiting of liquid corticosteroids in children with asthma. Pediatr Emerg Care 2006;22:397-401.

23 Kayani S, Shannon DC. Adverse behavioral effects of treatment for acute exacerbation of asthma in children: a comparison of two doses of oral steroids. Chest 2002;122:624-8.

24 Chang AB, Clark R, Sloots TP, et al. A 5- versus 3-day course of oral corticosteroids for children with asthma exacerbations who are not hospitalised: a randomised controlled trial. Med J Aust 2008;189:306-10.

25 Schuh $S$, Coates AL, Dick P, et al. A single versus multiple doses of dexamethasone in infants wheezing for the first time. Pediatr Pulmonol 2008;43:844-50.

26 Scarfone RJ, Fuchs SM, Nager AL, et al. Controlled trial of oral prednisone in the emergency department treatment of children with acute asthma. Pediatrics 1993;92:513-8.

27 Panickar J, Lakhanpaul M, Lambert PC, et al. Oral prednisolone for preschool children with acute virus-induced wheezing. N Engl J Med 2009;360:329-38. 


\section{Original article}

28 Corneli HM, Zorc JJ, Mahajan P, et al. A multicenter, randomized, controlled trial of dexamethasone for bronchiolitis. N Engl J Med 2007;357:331-9.

29 Tam DT, Ngoc TV, Tien NT, et al. Effects of short-course oral corticosteroid therapy in early dengue infection in Vietnamese patients: a randomized, placebo-controlled trial. Clin Infect Dis 2012;55:1216-24.

30 Lux AL, Edwards SW, Hancock E, et al. The United Kingdom Infantile Spasms Study comparing vigabatrin with prednisolone or tetracosactide at 14 days: a multicentre, randomised controlled trial. Lancet 2004;364:1773-8.

31 Dawson KP, Penna C, Penna AC. Tolerance and compliance of oral prednisolone therapy during acute childhood asthma. Aust J Hosp Pharm 1992;22:278-82.

32 Hall AS, Thorley G, Houtman PN. The effects of corticosteroids on behavior in children with nephrotic syndrome. Pediatr Nephrol 2003;18:1220-3.

33 Vallance K, Liu W, Mandrell BN, et al. Mechanisms of dexamethasone-induced disturbed sleep and fatigue in paediatric patients receiving treatment for ALL. Eur J Cancer 2010;46:1848-55.

34 Ailakis JG, Hope ME, Stafford L, et al. Comparison of paediatric steroid mixtures. Aust J Hosp Pharm 1998;28:246-9.

35 Francisca AH, Linus HP, Alejandro MA. Función Suprarrenal en Pacientes con Síndrome Bronquial Obstructivo Tratados con Corticoides Sistémicos (Informe Preliminar). Rev Chil Pediatr 2009;80:347-53.

36 Zora JA, Zimmerman D, Carey TL, et al. Hypothalamic-pituitary-adrenal axis suppression after short-term, high-dose glucocorticoid therapy in children with asthma. J Allergy Clin Immunol 1986;77:9-13.

37 Suarez $C R$, Rademaker D, Hasson A, et al. High-dose steroids in childhood acute idiopathic thrombocytopenia purpura. Am J Pediatr Hematol Oncol 1986;8:111-15.
38 de Sousa NG, Santa-Marta C, Morais-Almeida M. Systemic corticosteroid hypersensitivity in children. J Investig Allergol Clin Immunol 2010;20:529-32.

39 Kasper WJ, Howe PM. Fatal varicella after a single course of corticosteroids. Pediatr Infect Dis J 1990;9:729-32.

40 Feder HM, LaRussa P, Steinberg S, et al. Clinical varicella following varicella vaccination: don't be fooled. Pediatrics 1997;99:897-9.

41 Wu C-T, Tsai S-C, Lin J-J, et al. Disseminated varicella infection in a child receiving short-term steroids for asthma. Pediatr Dermatol 2008;25:484-6.

42 Dawson KL, Carter ER. A steroid-induced acute psychosis in a child with asthma. Pediatr Pulmonol 1998;26:362-4.

43 Lew DB, Higgins GC, Skinner RB, et al. Adverse reaction to prednisone in a patient with systemic lupus erythematosus. Pediatr Dermatol 1999;16:146-50.

44 Counts SJ, Baylink DJ, Shen FH, et al. Vitamin D intoxication in an anephric child. Ann Intern Med 1975;82:196-200.

45 Brito PN, Silva SE, Cotta JS, et al. Severe ocular hypertension secondary to systemic corticosteroid treatment in a child with nephrotic syndrome. Clin Ophthalmol 2012;6:1675-9.

46 Ularntinon S, Tzuang D, Dahl G, et al. Concurrent treatment of steroid-related mood and psychotic symptoms with risperidone. Pediatrics 2010;125:e1241-5.

47 Streck WF, Lockwood DH. Pituitary adrenal recovery following short-term suppression with corticosteroids. Am J Med 1979;66:910-14.

48 Hawcutt DB, Jorgensen AL, Wallin N, et al. Adrenal responses to a low-dose short synacthen test in children with asthma. Clin Endocrinol (Oxf) 2015;82:648-56.

49 Brown ES, Beard L, Frol AB, et al. Effect of two prednisone exposures on mood and declarative memory. Neurobiol Learn Mem 2006;86:28-34. 